\title{
THE HISTORY IN URBAN STUDIES: A COMMENT
}

\author{
RICHARD HARRIS \\ McMaster University
}

\author{
MICHAEL E. SMITH \\ Arizona State University
}

\begin{abstract}
A recent survey of the field of urban studies in this journal downplayed or overlooked the significance of urban history. In fact textbook coverage, and an analysis of urban publications in the Web of Science database, indicate that historical research has always played a major role in the field. For three reasons, it always should: the past shapes the present; the study of change encourages critical understanding; and the past offers many examples for use in comparative analysis.
\end{abstract}

$T_{\text {te }}$

he authors of a recent article in this journal asked a question that many of us dread, especially when framed by an undergraduate student, but which in the end we cannot long ignore: "What is Urban Studies?" (Bowen, Dunn, \& Kasdan, 2010). We are grateful to them for raising the question, and agree with some of what they have to say, but are concerned enough about one omission in particular, that we have been moved to respond.

Parts of the answer that Bowen et al. provide are reasonable, even predictable. We all know that urban studies tries to be interdisciplinary, even if it too often falls short. Other parts might provoke debate. For example, we were struck by their suggestion that lately urban subjects have fallen off, or at least down, the national agenda. We agree that they lack the profile that they had when Watts burned, but new concerns have replaced them, notably innovation and economic development, food security, and the health and environmental effects of sprawl. And we would have liked the authors to discuss the way so much of what passes for urban studies treats the city as a passive setting rather than an independent variable in its own right. But our immediate concern lies elsewhere.

In their survey and assessment, William Bowen et al. suggest that urban studies contains seven main subfields: urban sociology, geography, economics, governance, and planning, together with environmental studies and housing and neighborhood development. We agree that these subfields encompass much of the research that has been, and must continue to be, undertaken in the urban field. But, along with many other subscribers to the H-Urban discussion list, upon reading this article, we were struck by the absence from this list of urban history. After all, the writers who we personally have found most influential in shaping our thinking about cities-Lewis Mumford,

Direct correspondence to: Richard Harris, School of Geography and Earth Sciences, McMaster University, 1280 Main Street West, Hamilton, Ontario, Canada,L8S4K1.E-mail: harrisr@univmail.cis.mcmaster.ca.

JOURNAL OF URBAN AFFAIRS, Volume 33, Number 1, pages 99-105.

Copyright $(2011$ Urban Affairs Association

All rights of reproduction in any form reserved.

ISSN: 0735-2166.

DOI: 10.1111/j.1467-9906.2010.00547.x 
Jane Jacobs, David Harvey, and V. Gordon Childe-all made extensive reference to the historical experience of cities, even if they understood and used that experience in different ways. And surely, we thought, this short list of model luminaries is not wholly eccentric. ${ }^{1}$

So struck were we by the way Bowen et al. downplayed the role of history that we decided to prepare this written response. We argue that urban history has always played a major role in urban studies and that it always should. In making this argument, we draw upon some observations that were posted to the H-Urban list, as well as others that were sent to us privately. ${ }^{2}$ Although we cannot claim to speak for urban historians as a whole, we do believe that many would be in accord with our general line of argument.

\section{HISTORY'S PAST ROLE IN URBAN STUDIES}

Although Bowen et al. do not explicitly recognize it as a subfield in urban studies and although, as we will show, their methodology did not explicitly allow for it, history is everywhere in their survey. The authors reviewed 30 textbooks that were recently in use in urban studies programs at 26 universities across the United States. From this evidence, they concluded that the field might reasonably be divided into seven subfields. They then ran this list past nine "senior faculty," who had been chosen because of their broad knowledge of the field. One of the two main comments that these "veterans" provided was that urban history-along with anthropology and cultural studies- "might be added." In other words, experts recognized that urban historical research was an important presence in the field.

The authors did not choose to follow the elders' suggestion on this point. As a result, their surveys of the membership of the Urban Affairs Association and then of material published in the Journal of Urban Affairs (JUA), provided no opportunity for historical perspectives to make their presence felt. One example, dear to the heart of one of the present writers, is a co-authored article published in the JUA about a decade ago, which addressed the very historical question, "how the past matters" (Harris \& Lewis, 1998). Presumably, this was placed in the "other" category. Even so, in other parts of the recent survey paper, the importance of history seeps through.

It turns out, for example, that history is strikingly present in the 30 textbooks that they surveyed. Of these, at least eight are profoundly historical in character, and/or written by historians: Cronon's Nature's Metropolis, Gilfoyle's City of Eros, Gamm's Urban Exodus, Sugrue's Origins of the Urban Crisis, Caro's The Power Broker, Rybczynski's City Life, Hayden's Building Suburbia, and Friedman's The World Is Flat. Another work, Thomas Bell's Out of This Furnace, is a historical novel. Moreover, many other texts include substantial historical sections. In some cases, Bowen et al. note this in the point-form summaries of each book that they provide in an appendix. Thus, for example, they note that the sixth edition of Levy's Contemporary Urban Planning includes a section on the "history of planning," while the third edition of Macionis and Parillo's Cities and Urban Life includes a section on the "history of cities and new trends." In other cases, although Bowen et al. do not register the fact, it turns out that the books in question do contain substantial historical material. For example, about one-sixth of John Palen's The Urban World deals with the history of cities generally, and then in the United States, while The City Reader, edited by LeGates and Stout, includes a section on "the evolution of cities," together with contributions elsewhere from a number of writers whose work is steeped in historical thinking. These include Lewis Mumford, Peter Hall, Robert Fishman, and Dolores Hayden.

There is nothing new in the inclusion of historical material, of course. An influential early collection of 13 papers in the urban field included five that the editors considered to be essentially historical in character (Masotti \& Walton, 1976, p. 9). And, among the modern texts, even Robert Neuwirth's survey of squatter settlements, Shadow Cities, which focuses on a pressing contemporary issue, finds space to include a historical chapter on New York City, and a broad 
historically informed assessment entitled "The 21st Century Medieval City." It also contains significant historical material in the chapters that deal with specific cities, as when Neuwirth points out that the geçekondu of Istanbul take their present form in part because of a legacy of Ottoman traditions of land ownership. In contrast to the implication that historical research is marginal to urban studies, then, one could as plausibly argue from this evidence that it is virtually ubiquitous, and that its seepage saturates the field. But, although there is some room for debate, the authors themselves present enough evidence to suggest that urban history has, and continues to play, an important part in urban studies.

Other evidence may be cited to make an even stronger case. Take, for example, the way in which Bowen et al. choose to frame their analysis in the context of a "brief retrospective," which speaks about how the field of urban studies emerged during the political urban crisis of the 1960s, and has subsequently evolved in response to a changing public agenda. Like those textbook writers who see the need to frame modern cities in a long-range narrative, Bowen et al. imply that an understanding of the past matters if we want to make sense of urban studies as an academic field.

Or, more substantially, take the available evidence of published research. One of the key sources of evidence that Bowen et al. use to make their case is the publication record of the JUA. Although the record of the $J U A$ provides as good a snapshot of the field as any journal, all have disciplinary, geographical, theoretical, and/or political biases. Better, surely, to survey all of the major journals in the field, so that such biases cancel out. It is in fact easy to do this. The ISI Web of Science (WoS) database contains a balanced and comprehensive coverage of scientific research, published internationally in the English language. It includes every article or review published in the JUA, in journals such as Urban Studies that Bowen et al. mention in passing, and in others such as the International Journal of Urban and Regional Research, which they do not. For each item, among other things, the database contains keyword-searchable information on authors, titles, and abstracts, as well as year of publication. In its digital form, the WoS goes back to 1976 and can support a variety of types of analysis. One is of particular relevance here. Because the publishers of the WoS classify journals by their primary field of research ("sociology," "history," and so forth), it is possible to explore the changing contribution of such disciplines to a specific field of enquiry. In particular, it can help enormously in settling the question as to how large a role history plays in urban studies. The answer is, "huge."

To make the broadest possible survey of the WoS, we undertook a keyword search of the entire database using a single search term, "urban." It produced 47,864 hits, almost all in refereed journals. ${ }^{3}$ One of the fields of research recognized by ISI is "urban studies" and, not surprisingly, journals such as the JUA that are identified with this field contributed the largest share of articles on urban topics- $17.2 \%$ of the total (Table 1). Another way of saying this is that $82.8 \%$ of all articles on an urban topic were published in scholarly journals that were not primarily identified with urban studies. Among these, the most important fields were environmental studies, geography, and - the only other field in double digits-history. That history ranked above planning and well above economics, sociology, and political science is especially noteworthy because the WoS database does not yet include books, which is where historians, as opposed to other social scientists, still publish much of their research.

The significance of history is especially apparent when we consider the situation in the United States. The WoS database appears to classify publications according to their place of origin, so that it is possible to distinguish U.S.-based as opposed to international material. Since 1976, 20,476 (43\% of all) publications on an urban topic in the WoS database were produced in the United States. As contributors to this particular subset, "urban studies" journals again ranked first with $17.8 \%$ of the total. "History" ranked second (11.6\%), well ahead of any other field or discipline. It has slipped a little of late. When the U.S. subset is broken down further into older 
TABLE 1

Publications with "Urban" in the Title Tallied by Discipline

\begin{tabular}{|c|c|c|c|c|c|c|c|c|}
\hline \multirow[b]{3}{*}{ Field or Discipline } & \multirow{2}{*}{\multicolumn{2}{|c|}{$\begin{array}{c}\text { All Countries } \\
\text { All Years }\end{array}$}} & \multicolumn{6}{|c|}{ United States } \\
\hline & & & \multicolumn{2}{|c|}{ All Years } & \multicolumn{2}{|c|}{ Up to 1999} & \multicolumn{2}{|c|}{ 2000-2009 } \\
\hline & Rank & $\%$ & Rank & $\%$ & Rank & $\%$ & Rank & $\%$ \\
\hline Urban Studies & 1 & $17.2 \%$ & 1 & 17.8 & 1 & 17.1 & 1 & 19.0 \\
\hline Environmental studies & 2 & 13.2 & 3 & 8.9 & 5 & 8.6 & 4 & 9.5 \\
\hline Geography & 3 & 12.4 & 4 & 8.7 & 3 & 9.1 & 5 & 7.9 \\
\hline History & 4 & 10.8 & 2 & 11.6 & 2 & 12.8 & 3 & 9.8 \\
\hline Planning/development & 5 & 9.0 & 7 & 7.7 & 6 & 8.2 & 7 & 7.2 \\
\hline Economics & 6 & 6.9 & 6 & 7.9 & 4 & 8.9 & 8 & 6.5 \\
\hline Public health & 7 & 6.0 & 5 & 8.0 & 10 & 4.8 & 2 & 12.7 \\
\hline Architecture & 8 & 5.8 & & & & & & \\
\hline Sociology & 9 & 5.0 & 8 & 6.8 & 7 & 7.6 & 9 & 5.3 \\
\hline Political science & 10 & 3.6 & 10 & 3.8 & 9 & 5.0 & & \\
\hline Education & & & 9 & 6.3 & 8 & 5.5 & 6 & 7.6 \\
\hline Health policy & & & & & & & 10 & 3.3 \\
\hline Total number of articles & \multicolumn{2}{|c|}{47,864} & \multicolumn{2}{|c|}{20,476} & \multicolumn{2}{|c|}{12,643} & \multicolumn{2}{|c|}{7,216} \\
\hline
\end{tabular}

Note: Data are from the ISI-Web of Science database, 1976-2010, accessed by Richard Harris, September 16, 2010. Includes only Social Science Citation Index, Arts and Humanities Citation Index, and Conference Proceedings Citation Index for Social Science and Humanities. Only the top 10 disciplines are listed in each category.

publications (1976-1999) and newer (2000-2009), we can see that history's position has fallen to third place, in a group of disciplines that is both more varied and more bunched. But clearly, historical journals, and for the most part that means historical research, continue to make a major contribution to urban studies, within the United States and beyond.

\section{HISTORY'S NECESSARY ROLE IN URBAN STUDIES}

It is hardly likely that anyone will claim that the large role of historical research in urban studies has been a matter of chance, or passing circumstance. But, it may be worth reminding ourselves, by making explicit, some of the reasons why its role is important enough to be counted as necessary.

First, most scholars of urbanism and other social phenomena would probably agree that current conditions have grown out of those that prevailed in the recent past, and thus an understanding of past urban processes is crucial in order to understand cities today. A good example is provided by Toronto, which from the 1960s to the 1990s prided itself on having a well-used and well-run transit system. (Lately, because of a lack of investment, its light has dimmed.) At that time, civic boosters claimed that efficient transit embodied good planning. In fact, it depended in large part on the self-interested obduracy of the private company that held a transit monopoly until 1921. Because this company refused to extend its streetcar lines beyond city limits, early 20th century suburbs developed at walking city densities. In due course, these helped to support a dense network of transit routes (Harris \& Lewis, 1998). It is impossible to make sense of Toronto's postwar transportation system, then, without reference to that earlier phase of development. The local details are unique, but the general principle is valid everywhere.

A second reason for the importance of history in urban studies is that it allows an understanding of how changing contexts affect cities and urban affairs. An example relevant to the growth of 
urban studies is the issue of segregation. The degree and pattern of segregation of African Americans did not vary much between 1961 and 1971, but its significance certainly did, as blacks challenged their position in American society. Indeed, debates on almost any significant topic can evolve quite rapidly in ways that expose and revise our taken-for-granted assumptions. A striking example is the succession of beliefs that have shaped policy with respect to downtown, as these have mutated decade by decade (Abbott, 1993). Dramatic short- and medium-term shifts can occur, and in the long run assumptions that were once unquestioned come to appear quaint or incomprehensible. A historical perspective helps us anticipate, and come to terms with that fact, thereby encouraging a useful skepticism about current fads.

A third aspect of the importance of history is that it widens the range of cases that can be used for comparative analysis and theory building. In this sense, the use of history can be considered a subcategory of comparative analysis, a topic not discussed in the article by Bowen et al. Their focus on disciplines rather than topics or themes may have ruled out a consideration of comparison, but in fact all of the disciplines surveyed include comparative approaches. Comparative urbanism has seen a strong upswing in the number and scope of publications in most of these disciplines; the following works and those they cite provide numerous examples of the nature and growing importance of comparative urban studies across many disciplines: Briggs (2004), Nijman (2007), Sellers (2005), Smith (2009b), and Ward (2009). This trend is not identified by Bowen et al., however.

These sorts of observations, about how historical research may inform current debates, may be applied to all sorts of topics (Porter \& Reid, 2010). But, there is one line of argument that has particular application to the field of urban studies. For certain historical periods, cities have been defined in social or institutional terms. The medieval city is an example, a place that governed itself and that contained (and fostered) particular types of social and economic relationships, especially those of a commercial character. But arguably the most enduring characteristic of cities, one that almost invariably forms the basis of their definition, concerns their physical presence. They are dense, well-populated settlements with considerable investment in the built environment, and other infrastructural components. We can, and do, debate exactly how large, or how dense, a place has to be to count as urban, but hardly anyone doubts that size matters. The same principle applies to those thinned-out cities, suburbs. In the United States, but not so much elsewhere, suburbs are defined in part by having their own political identity. But even here density also comes into play-less than the city, more than the exurban or rural hinterland. It is almost impossible to think about a city, a suburb, or a metropolitan area without feeling its physical presence.

The physicality of the city matters because it endures in ways that constrain and shape the future (cf. Harris \& Lewis, 1998; Storper \& Manville, 2006). Individual buildings last decades and cost much to change or replace. Even more enduring is their arrangement, as this is defined by the boundaries of land parcels and the layout of streets, a fact that urban morphologists never cease to emphasize. To change layouts and patterns is enormously difficult, not just because of the money involved in acquiring sites but because of the unpredictably fraught politics. In large part, postwar urban renewal programs foundered on that particular reef. On a larger scale, the distribution of different types of workplaces, transportation routes, and so forth presents a significant challenge to those who want to make a city "work," however that is defined. The results can be an enduring and costly mismatch, for example, between suburban jobs and city residents, or vice versa. And on the largest scale of all, the present distribution of cities has an enormous inertia that, as sea levels continue to rise into the predictable future, we may learn to regret. The slow rebirth of New Orleans after Hurricane Katrina is a story with many heroes, and only a minority of observers would say that it has been a mistake. But if, in 2006, there had been no major urban settlement between Lake Pontchartrain and the Gulf of Mexico, what are the chances that we would be 
building one there now? The inertia of land ownership, and investments in infrastructure, almost guarantee that cities will be rebuilt. In other words, at all scales, the history of urban settlements matters because it constrains so obdurately how we live, and what we can do about it.

Urban history, then, should always be a major part of urban studies, and in at least two senses. First, it is always important that some research be done by people who have been trained in some type of historical research. They are likely to call themselves historians, archaeologists, historical geographers, economic historians, or something similar, but the labels themselves are unimportant. What matters are that they have the relevant skills that historical research requires. Among the more important are a knowledge of relevant sources, and of the difficulties associated with them; a sensitivity to change, and the complex ways in which this may work its way out; and a subtle awareness of the dangers and potentialities of making comparisons across time and space.

Second, and this brings us to our main reason for writing this commentary, it is equally important that there be a large audience for historical research among those who are interested in contemporary issues, an audience that recognizes the pervasive, if variable, significance of history. We have argued that such an audience does exist among those who work in the field of urban studies, including the readers of this journal and the textbook writers who help shape the thinking of a future generation. But the presence of this audience needs to be acknowledged and nurtured. We hope that our observations have nudged the field in this direction.

\section{ENDNOTES}

1 The influence of these writers is obvious, their historical credentials more variable. Mumford's best-known historical survey is The City in History (Mumford, 1961). Childe's key statement about cities was published in 1950 and is discussed by Smith (2009a). Since his doctoral dissertation, Harvey has been more of a consumer than a producer of historical research, but see his book on Paris for an original historical synthesis (Harvey, 2003). On Jacobs's use of history see Harris (2011).

2 We would like to thank the editors of H-Urban for allowing us to use the discussion list to fish for commentary. Because our survey was informal, we have not quoted or cited particular individuals. However, we would like to acknowledge comments from Carl Abbott, Amanda Seligman, and Joseph Heathcott.

3 The current WoS database amalgamated three published citation indexes, one of which pertained to science. It is possible to confine searches to the Social Sciences database and/or the Arts and Humanities database, and we used both. Both are comprised exclusively of refereed publications. In addition, ISI has recently added a database that covers conference proceedings in the Social Sciences and Humanities, some of which are not refereed. We also included this database in our analysis.

\section{REFERENCES}

Abbott, C. (1993). Five downtown strategies: Policy discourse since 1946. Journal of Policy History, 5(1), 5-27.

Bowen, W. M., Dunn, R. A., \& Kasdan, D. O. (2010). What is "urban studies"? Context, internal structure, and content. Journal of Urban Affairs, 32(2), 199-227.

Briggs, X. de S. (2004) Civilization in color: The multicultural city in three millennia. City and Community, 3, $311-342$.

Childe, V. G. (1950). The urban revolution. Town Planning Review, 21, 3-17.

Harris, R. (2011). The magpie and the bee: Jane Jacobs's magnificent obsession. In T. Mennel \& M. Page (Eds.), Does Jane Jacobs matter? (pp. 65-81). Washington, DC: American Planning Association (forthcoming).

Harris, R., \& Lewis, R. (1998). How the past matters: North American cities in the twentieth century. Journal of Urban Affairs, 20(2), 159-174.

Harvey, D. (2003). Paris, capital of modernity. New York: Routledge. 
Masotti, L. H., \& Walton, J. (1976). Comparative urban research: The logic of comparisons and the nature of urbanism. In J. Walton \& L. H. Masotti (Eds.), The city in comparative perspective (pp. 1-15). New York: Sage.

Mumford, L. (1961). The city in history: Its origins, its transformations, and its prospects. New York: Harcourt Brace.

Nijman, J. (2007). Introduction: Comparative urbanism. Urban Geography, 28, 1-6.

Porter, M., \& Reid, A. J. (2010). Today's toughest policy problems: How history can help. History and policy website. Available at http://www.historyandpolicy.org/papers/policy-paper-100.html, accessed October 6, 2010.

Sellers, J. M. (2005). Re-placing the nation: An agenda for comparative urban politics. Urban Affairs Review, 40, $419-445$.

Smith, M. E. (2009a). V. Gordon Childe and the urban revolution: An historical perspective on a revolution in urban studies. Town Planning Review, 80, 3-29.

Smith, M. E. (2009b). Sprawl, squatters and sustainable cities: Can archaeological data shed light on modern urban issues? Cambridge Archaeological Journal, 20(2), 229-253.

Storper, M., \& Manville, M. (2006). Behavior, preferences and cities: Urban theory and urban resurgence. Urban Studies, 43, 1247-1274.

Ward, K. (2009). Towards a relational comparative approach to the study of cities. Progress in Human Geography, $33,1-17$. 


\title{
RESPONSE TO "THE HISTORY IN URBAN STUDIES: A COMMENT"
}

\author{
WILLIAM M. BOWEN and RONNIE A. DUNN \\ Cleveland State University \\ DAVID O. KASDAN \\ Oakland University
}

$T_{1}$

he purpose of our paper "What is Urban Studies?" was to provide a general empirical description of the field, from its origin to the present. We sought to approach this problem as systematically and impartially as possible. At no time did our goals include normative prescriptions of what the field should or should not contain.

Our first step was to develop a set of categories for the large collection of scholarship that constitutes the field of urban studies. This was necessary to describe and analyze a huge body of literature. The benefits of this approach included identifying, elucidating, and facilitating discussion about differences among the categories of the constituent literature. We developed the category scheme by identifying prominent urban studies programs throughout the United States and then carefully examining the textbooks used in those programs. The process we employed was essentially an interactive one of tentatively stipulating categories, carefully culling the texts, and saying to ourselves "This one is like that one, and both are different from those others." We continually adapted and altered the categories in order to accommodate the information encountered in the collection of texts until we were satisfied that a maximally comprehensive category scheme was constructed.

Of course, the process of developing categories always has a drawback: it inevitably leads to a loss of information, indeed sometimes vital information that indicates shades of difference. Therefore, before proceeding to estimate the internal structure of the categories or apply it in a content analysis, we rigorously tested that the categories were exhaustive, exclusive, and as valid as possible. We did this through numerous structured interviews with pioneers in the field and other colleagues, during which we specifically asked whether the seven-category scheme was reasonable and complete. The great bulk of the responses we received were wholly supportive of the scheme. Moreover, only when we were satisfied with the congruence of our scheme did we attempt to further clarify the description of the field through our chosen methodologies.

Direct correspondence to: William M. Bowen, Maxine Goodman Levin College of Urban Affairs, Cleveland State University, 2121 Euclid Avenue, Cleveland,OH 44115-2214.E-mail: w.bowen@csuohio.edu.

JOURNAL OF URBAN AFFAIRS, Volume 33, Number 1, pages 107-110.

Copyright $(2011$ Urban Affairs Association

All rights of reproduction in any form reserved.

ISSN: 0735-2166.

DOI: 10.1111/j.1467-9906.2010.00548.x 
In the process of developing the categories, we had some fairly protracted and explicit discussions about history, both among ourselves and with the pioneers and colleagues. One line of argument was that history has an explicit constitutive role as a subdiscipline in urban studies, as Harris and Smith seem to advocate. The other was that history is a field unto itself that stands on its own and infuses all the other subdisciplines within urban studies. In this latter view, history is viewed more as a lens, frame, or perspective than an explicit subdiscipline. We considered both views at some length.

While a couple of pioneers and colleagues suggested we "might" include history as an explicit subdiscipline or category (indicating a choice, not a directive given to us by the pioneers as Harris and Smith would seem to prefer), the views of the majority of our interviewees either explicitly excluded history as a constitutive subdiscipline or were indifferent to its inclusion. For instance, in response to the question, we asked all of our pioneers and other interviewees whether the proposed list of seven subdisciplines leaves any disciplines out. One replied, "I think people have really tried to add other dimensions to it [urban studies] and to say that it's not just any social science research and not just anything about cities but things that relate to... the use of physical and social space within cities more than anything else." Another said, "Political science, sociology and to a little extent economics - but certainly political scientists and sociologistshave been the primary movers and shakers inside urban affairs from its outset." This, of course, counter-indicates including history as an explicit core subdiscipline. The same interviewee also went on to say, "What hasn't happened is that we haven't branched out nearly well enough or often enough to allied disciplines, such as history and, to a specific extent, psychology." Again, the phrase "branched out" implies a division between the constitutive "inside" disciplines (of political science, sociology, and economics) and the "outside" disciplines of history and psychology. Similarly, the term "allied" is used to describe the relation between urban studies and history and does not imply membership or inclusion of the discipline of history within urban studies. These and other similar comments seemed to lend credence to the view that history is a field unto itself that stands on its own and infuses all the others, serving in a complementary relation to urban studies within the more general category of academic disciplines that include both.

Indeed, insofar as Harris and Smith raise the normative point that historical perspectives should play a major role in urban studies, it seems difficult to imagine how any reasonable and responsible person might argue against them. Such perspectives are clearly important not only in urban studies but also in political science, sociology, psychology, anthropology, the other social sciences, and indeed the arts and humanities as well. Nevertheless, our objective was to provide a general empirical description of the field of urban studies, not to evaluate the corresponding facts. While a decision to accept a normative position or standard at least tentatively helps to create that standard, decisions to accept facts do not create those facts. Accordingly, our objective was not to advance a normative view but rather to provide a factual description of the field on the basis of carefully and systematically gathered evidence.

One such descriptive fact is that out of the 35,000 words contained in the 222 article titles and abstracts in our sample, the word "history" appears only eight times and "historical" is used only eleven times. This may be an anomaly of our sample, or perhaps an unfortunate state that the publishing period 1999-2007 largely ignored the subject of history in the field. Regardless of the explanation, it remains a descriptive fact that in our sample the words "history" or "historical" appeared in an extraordinarily small percentage of the articles. It is moreover difficult to imagine how one might account for this small percentage on the basis of the assumption that history is a core subdiscipline in urban studies. Even within (1) environmental studies and (2) urban planning, design, and architecture, the two most sparsely populated of the seven categories, the usage frequency of characteristic keywords vastly exceeds this. It is on the basis of such 
considerations that we were led to the conclusion that history is more properly viewed as a lens or perspective on urban studies than as a constitutive core subdiscipline.

We hasten to note that if asked our opinions or preferences about whether history should as a matter of normative standard be included as required subjects for students in urban studies, we would have no doubt that well-informed historical perspectives should be fundamental in the field. Without historical perspectives, it would not be possible to invoke any notions of change, human agency, the role of material circumstances in urban life, or the meaning of the events of the past. Without historical perspectives, there would be no way to learn from the past so as to better understand ourselves and our own cities in the present. Even the methodology of empirical studies depends on an understanding of data as history, thus extending its reach into many more social science disciplines. All of which attests to the importance of studying the urban "historically" in ways that are akin to the practices of many other social science fields. But while this sort of normative standard may be useful for evaluating urban studies and other fields, it does not alter or change the factual evidence that led us to conclude that history does not constitute one of the core subdisciplines.

Finally, we want to briefly address Harris and Smith's Table 1, along with their suggestion that a similar study to ours based upon the Web of Science might better characterize the field of urban studies. Such a study as they suggest may be feasible and worthwhile, and it may in some ways provide a grander view than ours, especially given that ours only described American urban studies. However, the study they suggest would be a very different one than ours, with an altogether different purpose and methodology.

The purpose of our research was focused upon providing a general empirical description of the field of urban studies as such, not upon enumerating the frequency of all articles that use the term "urban" throughout all other academic fields and disciplines (such as history), or that contain tangentially or otherwise urban-related topics. For instance, it was aside from our purpose to consider studies focused on urban education, urban public health policy, the effects of urbanization on psychological well-being, or a host of other topics all of which include the word "urban." Indeed the boundaries of our study more closely approximated the $17.2 \%$ of the articles listed in Harris and Smith's Table 1 as members of the field of Urban Studies rather than on the other $82.8 \%$ that are listed as belonging in other disciplines, such as Education, Political Science, or Sociology.

Also, because of our emphasis upon the disciplined use of sophisticated research methods, the internal and construct validity of our findings and conclusions were far superior to those that could ever occur on the basis of a simple tabulation of research articles. Of course a content analysis of articles drawn from the Web of Science could be done, and indeed one of us has recently completed such a study, albeit not of articles within the field of urban studies. However, the point is that the methodological demands of an investigation such as ours go way beyond those involved in a simple tabulation of articles. For instance, within our content analysis of articles in urban studies, the reliability of our assignment of articles to categories was painstakingly established using formal reliability tests. We went to considerable length to ensure that the assumptions of the statistical and analytical techniques were congruent with the data, and that were they implemented properly. As a result, our description of the field was disciplined by deep, long logical chains of reasoning through systematically acquired data carefully designed specifically for the stated purpose of our research. Our description of the field of urban studies was thus scientifically grounded in both phenomenological and fundamental theory, thereby enabling a reasonably high level of construct validity, certainly much higher than could ever come about through a simple tabulation. We also might add that we did duly acknowledge that we examined but a single journal for our content analysis and that therefore the external validity of our description was threatened by the possibility of a bias in the sample. 
As noted in our article, George Galster said that the field of urban studies has been "very contentiously defined" since its inception. He went on to say that the debate about the definition of the field had been resolved within 5-10 years of its inception. It appears that this view might have been premature, given this current commentary. Nevertheless, we stand by our research. The weight of testimonial and analytical evidence we encountered led us to view history as an important set of perspectives that stand on their own and infuse urban studies; but not to view history as one of the explicit constitutive subdisciplines that define the structure of the field. Whether it should be this way or not is a different matter. 